\title{
Aggression management in a children's hospital setting
}

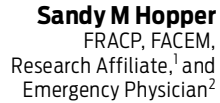

Franz E Bab MD, FRACP, FACEP,

Head of Research, Emergency Research Group,' and Associat Professor

Claire E Stewart PGDipENB, RN Nurse Educator

Jia Wei Woo

BSc, MB BS, Former Student, ${ }^{3}$ and Resident Medical Officer

1 Murdoch Children Research Institute University of Melbourne, Melbourne, VIC

2 Royal Children's Hospital, Melbourne, VIC

3 University of Melbourne Melbourne, VIC.

4 Eastern Health, Melbourne, VIC

sandy.hopper@ rch.org.au

MJA 2012; 196: 198-201 doi: 10.5694/miall.10257 \section{aggression involves a dynamic set of} events, with simultaneous evolving priorities requiring rapidly changing actions. A preplanned, systematic team approach is ideal to manage this kind of event. ${ }^{9,13}$ Reports regarding the organisational structure of a violence management team in emergency departments (EDs) and general hospitals are scarce. ${ }^{13,14}$

Although aggression is less frequent in children's hospitals than in adult hospitals, it does occur. In response to the recognition of aggression as a problem, ${ }^{15}$ and to some sentinel events, a formal system of aggression management was implemented to improve clinical risk, staff safety and patient care. We describe the system's development, structure and implementation, and present utilisation data from the first year of its operation.

\section{Methods}

\section{Setting}

The program was developed at the Editorial p 154

Royal Children's Hospital Melbourne

Abstract

Objectives: To describe the development, structure and implementation of a formal system of aggression management, and to document its utilisation during the first year of operation.

Design and setting: A prospective audit at the Royal Children's Hospital, a major children's hospital in Melbourne.

Main outcome measures: Analysis of utilisation patterns from prospective data forms augmented by retrospective review of security logs and medical records for 14 months from launch in December 2006.

Results: Staff from four different clinical areas, led by an emergency consultant and a hospital administrator, made up the rostered multidisciplinary "code grey" team. Over 14 months, there were 104 incidents when the team was activated, involving patients in 75 cases and visitors in 29 cases. Incidents occurred at equal frequency on wards and in the emergency department. Patients involved were most commonly affected by a mental disorder, frustration and/or a developmental disability. The apparent cause of visitor aggression was mainly frustration and occasionally drugs. The majority of patient aggressors showed physical aggression towards people or objects or self-harming behaviour. Visitor aggressors were mostly verbally aggressive (and occasionally physically violent). For patients, the team used verbal de-escalation (56/75 events), physical restraint (34/75), sedation (23/75) and mechanical restraint (15/75). For visitors, verbal de-escalation occurred in 17/29 cases and 10/29 visitors left or were removed. Several patient and staff injuries were documented.

Conclusions: An aggression management team can be established in a children's hospital setting. This team structure provides a useful response to concerns about staff safety and optimal patient care.

$(\mathrm{RCH})$, a 310-bed tertiary children's hospital. In 2007, the ED saw 67000 presentations, of which 600 related to mental health concerns. Although the $\mathrm{RCH}$ is gazetted under the Victorian Mental Health Act as an approved facility for the care of mental health patients, the mental health inpatient unit is located at another campus. It is due to relocate to the main campus in early 2012.

\section{Definition of the problem}

A review of the care of patients with mental health disorders in the ED showed that security incidents were not infrequent. ${ }^{15}$ No hospital-wide data were available and no systematic hospital response was available. Incidents of aggression were managed in an ad hoc fashion by staff present at the incident. Security staff at the $\mathrm{RCH}$ were not specifically trained to handle such incidents. Staff had been verbally abused and some assaulted (Claire Stewart, Nurse Educator, $\mathrm{RCH}$, personal communication, 25 Sep 2008).
This, combined with recent state government reports on violence in nursing, ${ }^{13,14}$ led to the formation of a multidisciplinary working group. This group recommended policy and protocol development, education and training as well as the formation of a hospital-wide systematic team response. Existing resources were to be used and directed towards management of aggression when de-escalation measures had failed. In keeping with local nomenclature, this team was called the "code grey" team. A project officer was appointed and, in consultation with stakeholders, rewrote or generated protocols and guidelines on the detection and management of aggression. ${ }^{16}$

\section{Team activation and responses}

A description of the code grey response is on the $\mathrm{RCH}$ Clinical Practice Guidelines site. ${ }^{16}$ The team can be activated by any staff member in response to a perceived or actual threat to themselves or others, where verbal de-escalation has either failed 
or is inappropriate. This includes threats or acts of self-harm or absconding. The team can also be activated to prevent aggression in a patient with a previous history of aggression (a pre-emptive code grey).

The eight-person team assembles near the event and receives handover from staff members involved. The team actions vary according to the aggressor, the behaviour and the response to interventions. The prime method is continued verbal de-escalation coupled with the physical appearance of eight staff gathering at the site. As a last resort, five-person physical restraint and chemical restraint may be used. If sedation is indicated, collaborative voluntary oral sedation is preferred over involuntary intramuscular sedation (generally haloperidol and midazolam in combination). ${ }^{16}$ Mechanical restraint with padded straps is used as a temporary manoeuvre while sedation is titrated to effect. Management of patients in the ED locked "safe room" (similar to seclusion) is an option for emergency patients.

Management of patients (to whom the hospital and staff have a duty of care) is delineated from the approach to aggression by visitors. A further differentiation is made when the aggression is judged too dangerous, for example, an armed aggressor. In this instance the team response does not occur, or would stand down in favour of a security-only response with or without police involvement. This response is named "code black".

\section{Team organisation}

The multidisciplinary team comprises two security officers, a senior ED doctor (team leader), four nurses (from four different wards, including the ED and an adolescent ward) and a member of the hospital administration (to provide logistical support and act as team leader when the aggressor is a visitor). Each area internally rosters trained members. Team membership varies from that of other institutions in that orderlies are absent and nurses play an important role in restraint when required.

Staff member roles are specified in guidelines and policy, and every team member is specifically trained. ${ }^{16}$

\section{Education}

A local mental health organisation trained staff in management of clinical aggression (MOCA). The course teaches prevention, early recognition and management of violence, and restraint and self-defence techniques.

The MOCA program was initially delivered to 110 staff, the number required to reliably provide a 24-hour full-team response. Ultimately, 500 staff underwent MOCA training.

For 2 months preceding the system launch, regular drills tested the activation system and team responses.

\section{Evaluation and monitoring}

A standardised reporting form was completed by the staff member who activated the code grey response and by the team leader. Security and switchboard logs acted as a backup for recording the events. After the development and implementation phase, the project officer handed maintenance and consolidation tasks to hospital occupational health and safety services.

\section{Study design, data collection and analysis}

Over 14 months from launch in December 2006, a prospective observational study was conducted, with $\mathrm{RCH}$ ethics committee approval as a quality-of-care audit. Primary case identification occurred via a prospective reporting form and secondarily from security, switchboard and hospital risk management records entries and retrospective medical record reviews. Information collected included event time and location, characteristics of the aggressor, nature of aggression, actions of the team and outcome. Adverse outcomes were reported subjectively.

Data were entered into EpiData, version 3.1 (EpiData Association, Odense, Denmark) and descriptively analysed.

\section{Results}

Over 14 months, 135 separate code grey incidents were recorded on switchboard and security reports. For 31 incidents, no further information was available from secondary sources. Thus descriptive data were available for 104 incidents. Incidents occurred

\begin{tabular}{|c|c|c|c|}
\hline \multicolumn{4}{|c|}{1 Time and place of code grey events } \\
\hline & $\begin{array}{l}\text { Total sample } \\
\qquad(n=104)\end{array}$ & $\begin{array}{l}\text { Patient events } \\
\qquad(n=75)\end{array}$ & $\begin{array}{l}\text { Visitor events } \\
\quad(n=29)\end{array}$ \\
\hline \multicolumn{4}{|l|}{ Time of event } \\
\hline In hours* & 50 & 33 & 17 \\
\hline After hours ${ }^{\dagger}$ & 53 & 41 & 12 \\
\hline Unknown time & 1 & 1 & 0 \\
\hline \multicolumn{4}{|l|}{ Place of event } \\
\hline Inpatient area & 41 & 27 & 14 \\
\hline Emergency & 39 & 33 & 6 \\
\hline Other & 24 & 15 & 9 \\
\hline
\end{tabular}

at almost equal frequency on wards $(41 ; 39.4 \%)$ and in the $\operatorname{ED}(39 ; 37.5 \%)$. The remainder occurred in corridors, stairways, operating theatres, clinics, lifts, garden and medical imaging areas (Box 1). Half of all incidents occurred after hours. While patient incidents were more likely to occur out of hours and in the ED, visitor incidents were more likely to occur in hours and on the wards.

Incidents involved patients in 75 cases (involving 40 different patients) and visitors in 29 cases. Of the 40 patients, there were 16 males and 24 females. One-third of patients were the subject of more than one code grey event. The age range for patients was 6-24 years (median, 15 years). Three patients were aged over 18 years and were long-term $\mathrm{RCH}$ patients who had not yet been transferred to adult care. These patients had a long history of psychiatric disorders and all required the use of physical restraint.

The condition of the aggressor is listed in Box 2. Patients were more likely to have pre-existing psychiatric or developmental problems, whereas for visitors, frustration was the most frequently recorded issue. A small number of visitors were mentally unwell or affected by drugs or alcohol.

While verbal aggression was extremely common in both groups, physical violence was uncommonly displayed by visitors. Self-harm and risk of absconding in patients (Box 2) were usually accompanied by other forms of aggression.

Verbal de-escalation alone (in 22 of 75 cases) or simply the presence of the team (in three cases) was sometimes sufficient. However, over half the 
2 Condition of aggressor and type of aggression in code grey events

\section{Total Patients Visitors}

$\begin{array}{lccc}\text { Condition of aggressor* } & & & \\ \text { Psychiatric condition } & 23 & 20 & 3 \\ \text { Frustrated } & 36 & 11 & 16 \\ \text { Developmental delay } & 11 & 6 & 0 \\ \text { Medical condition } & 7 & 8 & 1 \\ \text { Affected by drugs/alcohol } & 14 & 58 & 26 \\ \text { Type of aggression* } & & 30 & 6 \\ \text { Verbal } & 84 & 34 & 4 \\ \text { Physical (towards objects) } & 36 & 28 & 0 \\ \text { Physical (towards people) } & 38 & 13 & 0 \\ \text { Self-harming behaviour } & 28 & 4 & 0 \\ \text { Threatening to abscond } & 13 & 4 & \\ \text { Pre-emptive code grey } & & & \end{array}$

* Some aggressors were affected by more than one condition and displayed more than one type of aggression. $†$ A code grey activated to prevent aggression in a patient with a previous history of aggression.

\section{Interventions by team}

\begin{tabular}{lcc} 
Interventions* & $\begin{array}{c}\text { Patient event } \\
(n=75)\end{array}$ & $\begin{array}{c}\text { Visitor event } \\
(n=29)\end{array}$ \\
\hline Verbal de-escalation (total) & 56 & 17 \\
$\begin{array}{l}\text { Verbal de-escalation } \\
\text { (as sole intervention) }\end{array}$ & 22 & 16 \\
Restraint (any type) & 40 & 2 \\
Physical restraint & 34 & 2 \\
Chemical restraint & 23 & 0 \\
Mechanical restraint & 15 & 0 \\
Confined in ED safe room & 11 & 0 \\
Departed voluntarily & 3 & 4 \\
Escorted from hospital by security & 1 & 5 \\
Escorted to another hospital by & 0 & 1 \\
police and CAT team & 3 & 2 \\
No intervention & 2 & 1 \\
Intervention not recorded & & \\
\hline
\end{tabular}

$\mathrm{ED}=$ emergency department. CAT = crisis assessment and treatment (community mental health crisis team). * Some aggressors received more than one intervention. treatment team (Box 3). A second visitor was physically restrained from striking a patient.

In 90 incidents, the presence or absence of adverse outcomes was documented. Overall, two team members were struck by patients and one member of the team was spat on. Two other staff members were struck by patients, but it is unclear from the reports whether this was before the arrival of the aggression management team or during the code grey event. No serious injuries resulted to staff. Two patients sustained self-inflicted minor injuries (head bruising and cuts to the hands). One visitor inflicted facial fractures on another visitor, also before arrival of the aggression management team. No patient suffered an adverse event as a result of physical or chemical restraint.

\section{Discussion}

To our knowledge this is the first report of a systematic approach that a general children's hospital has taken to manage violence and aggression. This prospective series shows some findings that are relevant to other children's hospitals. Aggression which is refractory to de-escalation by general clinical staff, while proportionately infrequent (135 incidents from 260000 total episodes of care hospital-wide), is seen in patients and visitors and is common enough to warrant a specific and well designed response. In looking at the code grey incidents, verbal aggression is prevalent and physical aggression and selfharm is frequent. Even when stipulated as a last resort, restraint is used in over half of cases involving patients, and a substantial proportion of visitors (over one-third) were either escorted from the hospital or left voluntarily.

Self-harm and the risk of absconding may not appear to constitute frank aggression, but we believe the response to such behaviour best sits within an aggression management team framework.

Aggression management in a general paediatric setting differs from that in the adult ED or inpatient mental health setting.,13,17-19 Aggression is much less frequent. Substance misuse is a frequent contributor to violence in adult EDs but was less frequently seen as a contributor in the paediatric setting. In our series, intoxication was more common in visitors than patients.

As expected, medical conditions were more prominent in our study than in mental health areas. Females were more likely to be aggressors than males; this was possibly related to the higher incidence of self-harm, depression and anxiety in females than males. ${ }^{20,21}$ Reports from both adult and combined adult and paediatric health care settings describe about twice as many incidents in the ED as in wards ${ }^{13}$ but the majority of incidents occurred outside the ED. This is an important consideration when planning the reach and composition of a hospital-wide aggression response team.

Parents and carers, to whom the hospital owes no medical duty of care, account for a higher number of incidents than in adult EDs. ${ }^{4}$ The aetiology of this aggression is commonly frustration, and management relies on verbal de-escalation and removal of the aggressor from the hospital. In such cases, the hospital management representative became the team leader, rather than a clinical staff member. Restraint was only applied in the extreme circumstances of a mentally unwell parent or a relative perpetrating actual interpersonal violence.

In aggression management, patients and staff are potentially at risk of physical ${ }^{22}$ or emotional harm and possible legal action. In this series, no patient was injured during physical or chemical restraint. Training of staff involved in the code grey teams needs to reflect that restraint use is a matter of last resort, and close patient monitoring of sedated patients is critical to avoid adverse events. $^{23}$

Initial challenges to the formation of our code grey response teams included the lack of pre-existing paediatric models, insufficient security support and the absence of staff able to provide physical support. Balanced against this was the recognition by all stakeholders of the need for cooperation with nursing and medical staff volunteering to participate in the teams. The program continues to operate and has been subject to only minor changes. Like many new 
projects, continued efforts are required to maintain hospital management engagement.

Many elements of this program, such as policy and procedure development, team organisation, education and ongoing evaluation can be adapted by other institutions. Key factors to be considered in a modified model are the age range of patients cared for by the institution, the presence or absence of adult patients, the quality, presence and availability of on-site mental health services and the incidence of drug and alcohol-related presentations. Compared with many adult hospital models, the $\mathrm{RCH}$ team is predominantly comprised of clinical staff. While this facilitates a focus on care and compassion for behaviourally disturbed adolescents (with a high proportion of females, intellectually disabled and at-risk young people), this structure may be understrength to manage large, strong or particularly violent patients.

\section{Limitations of the study}

Data were mainly derived from the manually completed code grey report forms and supplemented by other, retrospective databases such as switchboard logs, risk management entries and medical records. Some elements of the data were subjective, based on the assessment of the team leaders. Application of these results to other hospitals would need to take into account particular local factors and individual legal and administrative processes.

\section{Conclusion}

Incidents of aggression in a paediatric hospital are less frequent than those in an adult or mixed-age hospital and have different contextual origins, yet physical and chemical restraint is not infrequently required. An aggression management team provides a useful response to concerns about staff safety and optimal patient care.

Acknowledgements: Grants were received from the Murdoch Childrens Research Institute and the Operational Infrastructure Support Program of the Victorian Government.

Competing interests: No relevant disclosures.

Received 6 Mar 2011, accepted 5 Dec 2011.

1 Cameron L. Verbal abuse: a proactive approach. Nurs Manage 1998; 29: 34-36.

2 Oztunç G. Examination of incidents of workplace verbal abuse against nurses. J Nurs Care Qual 2006; 21: 360-365.

3 Rippon TJ. Aggression and violence in health care professions. J Adv Nurs 2000; 31: 452-460.

4 Knott JC, Bennett D, Rawet J, Taylor DM. Epidemiology of unarmed threats in the emergency department. Emerg Med Australas 2005; 17: 351-358

5 Woolfenden S, Dossetor D, Nunn K, Williams K. The presentation of aggressive children and adolescents to emergency departments in Western Sydney.J Paediatr Child Health 2003; 39: 651-653.

6 Zernike W, Sharpe P. Patient aggression in a general hospital setting: Do nurses perceive it to be a problem? Int J Nurs Pract 1998; 4: 126-133.

7 Duxbury J, Whittington R. Causes and management of patient aggression and violence: staff and patient perspectives. J Adv Nurs 2005; 50: 469-478.

8 Fitzsimmons P. Management of violent patients in a general hospital. Aust Nurses J 1991; 21: 11-12.

9 Foster C, Bowers L, Nijman H. Aggressive behaviour on acute psychiatric wards: prevalence, severity and management.J Adv Nurs 2007: 58: 140-149.

10 Sukhodolsky DG, Cardona L, Martin A. Characterizing aggressive and noncompliant behaviors in a children's psychiatric inpatient setting. Child Psychiatry Hum Dev 2005; 36: 177-193.
11 Liebelt EL. Therapeutics and toxicology issues associated with the agitated, violent, or psychotic pediatric patient. Curr Opin Pediatr 2004; 16: 199-200.

12 Ferns T. Terminology, stereotypes and aggressive dynamics in the accident and emergency department. Accid Emerg Nurs 2005; 13: 238-246.

13 Policy and Strategic Projects Division, Victorian Government Department of Human Services. Occupational violence in nursing: an analysis of the phenomenon of code grey/black events in four Victorian hospitals. Melbourne: Department of Human Services, 2005. http://www.health. vic.gov.au/_data/assets/pdf_file/0008/17585/ codeblackgrey.pdf (accessed Jan 2012).

14 Nurse Policy Branch, Victorian Government Department of Human Services. Victorian taskforce on violence in nursing: final report. Melbourne: Department of Human Services, 2005. http://www.health.vic.gov.au/_data/ assets/pdf file/0007/17674/victaskforcevio.pdf (accessed Jan 2012)

15 Stewart C, Spicer M, Babl FE. Caring for adolescents with mental health problems: challenges in the emergency department. J Paediatr Child Health 2006; 42: 726-730.

16 Clinical Practice Guideline Group. Emergency restraint and sedation - code grey. Melbourne: Royal Children's Hospital, 2006. http://www. rch.org.au/clinicalguide/cpg.cfm?doc_id = 5243 (accessed Jan 2012)

17 Frey RE, Weller J. Rehab rounds: behavioral management of aggression through teaching interpersonal skills. Psychiatr Serv 2000; 51: 607-609.

18 Morrison EF. An evaluation of four programs for the management of aggression in psychiatric settings. Arch Psychiatr Nurs 2003; 17: 146-155.

19 Downes MA, Healy P, Page CB, et al. Structured team approach to the agitated patient in the emergency department. Emerg Med Australas 2009; 21: 196-202.

20 Kulkarni J. Women's mental health. Aust N Z J Psychiatry 2008; 42: 1-2.

21 Yip KS. Gender differences in mental illness in Hong Kong. Adm Policy Ment Health 2003; 30 361-368.

22 Coburn VA, Mycyk MB. Physical and chemical restraints. Emerg Med Clin North Am 2009; 27: 655-667.

23 Dorfman DH. The use of physical and chemical restraints in the pediatric emergency department. Pediatr Emerg Care 2000; 16: 355-360. 